\title{
Computer Simulation on Surface Crack Growth of Recycled Concrete Beams with Fractals
}

\author{
Hongquan Sun \\ Department of Computer Science \& Engineering \\ Guangzhou College of Technology and Business \\ Guangzhou 510850, China \\ 781104370@qq.com
}

Key words: computer simulation; fractal dimension; recycled concrete beam; crack

\begin{abstract}
.
Three recycled concrete beams with the different gradation of coarse aggregates under concentrated load are presented. By using fractal theory, the distribution of the surface crack growth of the recycled concrete beams is analyzed. The results indicate that the surface crack of three recycled concrete beams show self-similarity of fractal behavior. The relationships between the fractal dimension and the damage variable and loads are established separately. The fractal dimension reflects the destructive degree of the recycled concrete beams.
\end{abstract}

\section{Introduction}

With the rapid development of city construction, many old buildings have reached their service life. Combining with the reconstruction of city and other projects, a lot of dismantled concrete shows an increasing trend for years. Most of the waste concrete blocks are shipped to the outskirts and deposited in the open air so that they not only waste resources and pollute the environment. By crushing, washing and grading the waste concretes we may get the recycled coarse aggregate. Using the recycled coarse aggregate as a part or whole of the aggregate, instead of natural aggregate, mixed with normal concretes the recycled coarse aggregate concrete is obtained [1]. Recycled crushing aggregates obtained from the waste concrete not only solve the problem of the lack of natural aggregate but also give the way to recycle the waste concrete.

The concrete beam is a common and important component in the concrete structure. For recycled coarse aggregate concrete, it has a great significance in the practical engineering application to study the bending capacity of the recycled coarse aggregate concrete beams and the law of surface crack extension. In this paper, the features of flexural performance and crack extension of the three recycled coarse aggregate concrete test beams are studied with fractal theories.

\section{Experimental Overview}

\subsection{Specimen design}

Three recycled coarse aggregate concrete simply supported beams are designed with the different gradations from $5 \mathrm{~mm}$ to $16.5 \mathrm{~mm}$ (RB-1), $16.5 \mathrm{~mm}$ to $31.5 \mathrm{~mm}$ (RB-2) and $5 \mathrm{~mm}$ to 31.5 mm (RB-3) respectively. The recycled coarse aggregate concrete beams are called designed test beams in this paper. The parameters of the designed test beams are shown in table 1. 
Table 1 Parameter of Designed Test Beams

\begin{tabular}{ccccc}
\hline $\begin{array}{c}\text { Symbols of } \\
\text { Specimen }\end{array}$ & $\begin{array}{c}\text { Gradation } \\
(\mathrm{mm})\end{array}$ & $\begin{array}{c}\text { Strength of } \\
\text { Concrete }\end{array}$ & $\begin{array}{c}\text { Section } \\
\text { Size }\left(\mathrm{mm}^{3}\right)\end{array}$ & $\begin{array}{c}\text { Protective } \\
\text { Layer } \\
\text { Thickness } \\
(\mathrm{mm})\end{array}$ \\
\hline RB-1 & $5-16.5$ & C30 & $2000 \times 300 \times 150$ & 20 \\
RB-2 & $16.5-31.5$ & C30 & $2000 \times 300 \times 150$ & 20 \\
RB-3 & $5-31.5$ & C30 & $2000 \times 300 \times 150$ & 20 \\
\hline
\end{tabular}

\subsection{Experimental Results}

The cracking loads of the three test beams are roughly equal. And the cracking loads are related to the ultimate tensile strength of the recycled concrete beams. After the test beam cracking, the strain on the steel bar increases with some concretes unloading. Along with the load increasing, the surface cracks expand gradually. At the same time, the width of cracks increases. Under the ultimate loads the distribution of the surface cracking of the three test beams is shown in figure 1.

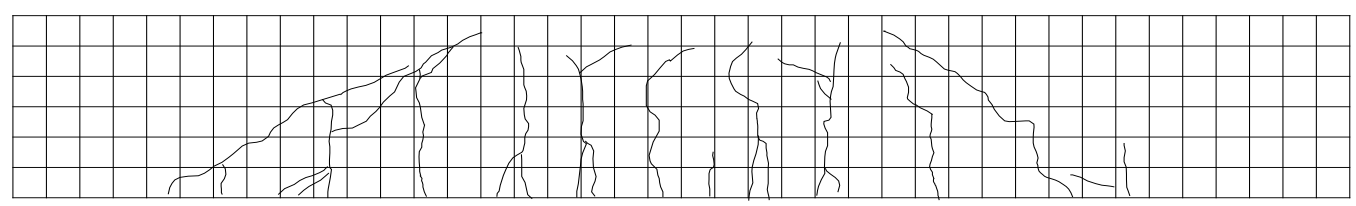

(a) RB-1

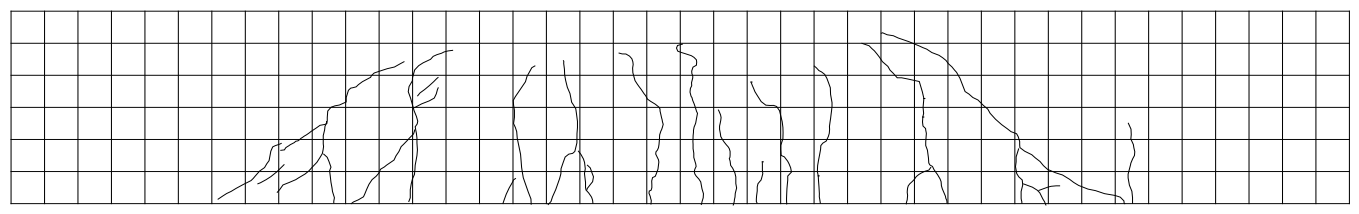

(b) RB-2

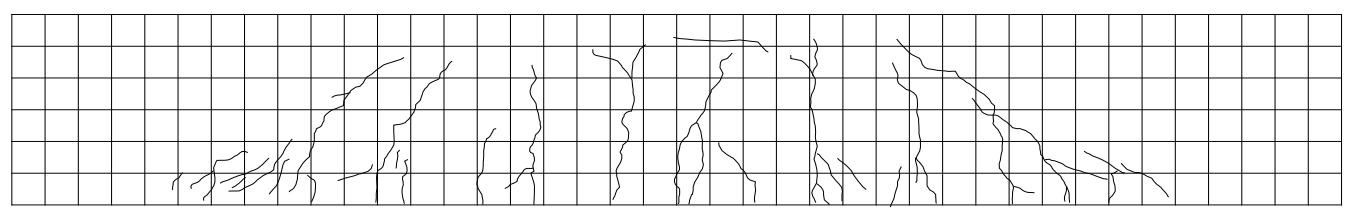

(c) RB-3

Fig. 1 The Distribution of the surface cracking of the three test beams

\section{Fractal Description of Surface Cracks}

\subsection{Calculation of Fractal Dimension}

The crack in concrete member is irregular. The characteristics of the fracture are described by observing the number and density of cracks qualitatively. But due to the expansion of crack is complex, it is difficult to determine the characteristics of each crack. In recent years, fractal theory is applied to describe the complexity of the crack extension path quantitatively [2].

Fractal dimension of the fracture on the component surface is obtained by the method of counting-box [3-4]. The basic steps are covering cracks with the box with side length $r$ and counting the number of the boxes which cover the cracks, $N(r)$. Then by changing $r$, the side length 
of boxes, we have the $N(r)$ responding. Finally the curve of $\ln N(r)-\ln r$ is obtained (see Fig. 2). The calculating formula of fractal dimension is given by

$$
D=-\lim _{r \rightarrow 0} \frac{\ln N(r)}{\ln r}
$$

\subsection{Fractal Dimension of the Cracks on Test Beam Surfaces}

The box side $\mathrm{r}$ takes the lengths from $30 \mathrm{~mm}$ to $150 \mathrm{~mm}$. Under different $r$, we have different $N(r)$. The statistical results are shown in Table 2.

Table 2 Statistical Results of $r$ and $N(r)$

\begin{tabular}{|c|c|c|c|}
\hline \multirow{2}{*}{$\begin{array}{c}\text { Box Sides } \\
r(\mathrm{~mm})\end{array}$} & \multicolumn{3}{|c|}{ Box Number $\quad N(r)$} \\
\hline & RB-1 & RB-2 & RB-3 \\
\hline 150 & 8 & 8 & 8 \\
\hline 120 & 13 & 10 & 14 \\
\hline 110 & 16 & 12 & 15 \\
\hline 100 & 17 & 16 & 16 \\
\hline 90 & 21 & 17 & 16 \\
\hline 80 & 24 & 19 & 25 \\
\hline 70 & 28 & 28 & 27 \\
\hline 60 & 35 & 29 & 33 \\
\hline 50 & 40 & 42 & 36 \\
\hline 40 & 56 & 50 & 51 \\
\hline 30 & 76 & 68 & 67 \\
\hline
\end{tabular}

According to the principle of the calculation of fractal dimension, the MATLAB language is used to fit the curve of $\ln N(r)-\ln r$ of the cracks on the test beam surface[5-6]. The absolute value of the slope of the curve of $\ln N(r)-\ln r$ is the fractal dimension of the cracks on the test beam surfaces. Table 3 gives the fractal dimension of the three test beams.

Table 3 Fractal Dimension of the Three Test Beams

\begin{tabular}{ccc}
\hline $\begin{array}{c}\text { Symbols of } \\
\text { Specimen }\end{array}$ & $\begin{array}{c}\text { Fractal Dimension } \\
(\mathrm{D})\end{array}$ & $\begin{array}{c}\text { Correlation Coefficient } \\
\left(\mathrm{R}^{2}\right)\end{array}$ \\
\hline RB-1 & 1.296 & 0.991 \\
RB-2 & 1.377 & 0.993 \\
RB-3 & 1.258 & 0.988 \\
\hline
\end{tabular}

From Table 3 we know that the coarse aggregates with different grading have a significant impact on the crack developing of the test beams. The fractal dimension of RB-3 is the smallest. It indicates that degree of damage of RB-3 is minimized during the process of damage. A large number of studies have shown that the fractal dimensions of the cracks on concrete component surface are between 1.10 and 1.90 generally [5]. They are usually divided into three categories: 
1.10 to 1.40 for linear distribution, 1.30 to 1.60 for the planar distribution and 1.50 to 1.90 for meshed distribution. The cracks on recycled coarse aggregate concrete test beams are linear distribution and their fractal dimensions are between 1.10 and 1.40.

By comparing the fractal dimension of the three test beams we have that the fractal dimension of RB-2 is the largest, which of RB-1 is second and which of RB-3 is the least. The test beam RB-2 of the recycled coarse aggregate contains many micro fractures and its crack developing is relatively faster under loading. While the test beam RB-1 contains some broken slurry particles which is easier to break and can't prevent the developing of cracks effectively. The test beam RB-3 is dense relatively and the cracks on it develop slowly.

\section{Relationship between the Fractal Dimension and Mechanical Parameters}

4.1 Relationship between fractal dimension and loading ratio

With the load increasing the damage degree of the test beam increases and its surface cracks are also expanding. Figure 2 shows a good linear relationship between the fractal dimensions under different loads and the ratio of the load to the limit load (Loading Ratio). With the increasing of the loading ratio, the fractal dimensions of surface crack of the test beam are also growing. This illustrates that the damage degree of test beam is also more and more serious.

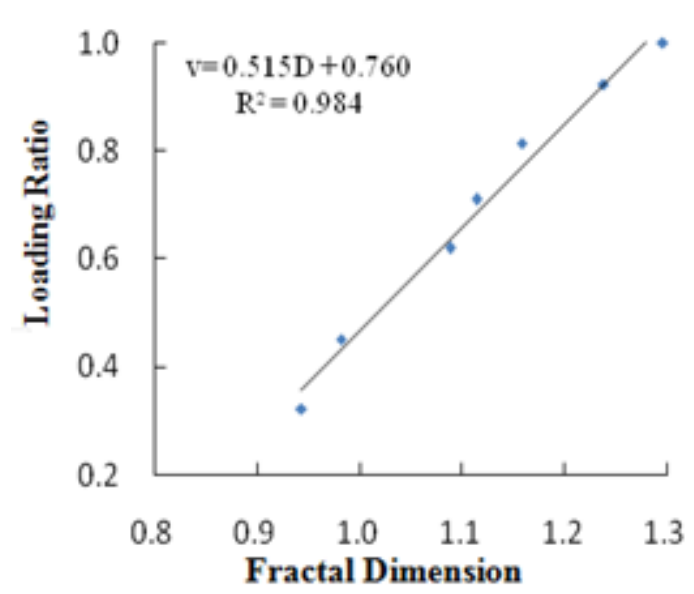

(a) RB-1

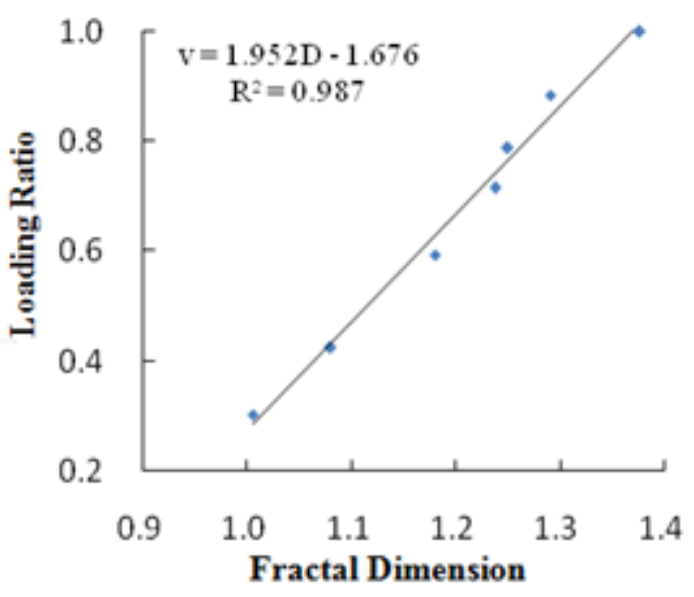

(b) RB-2

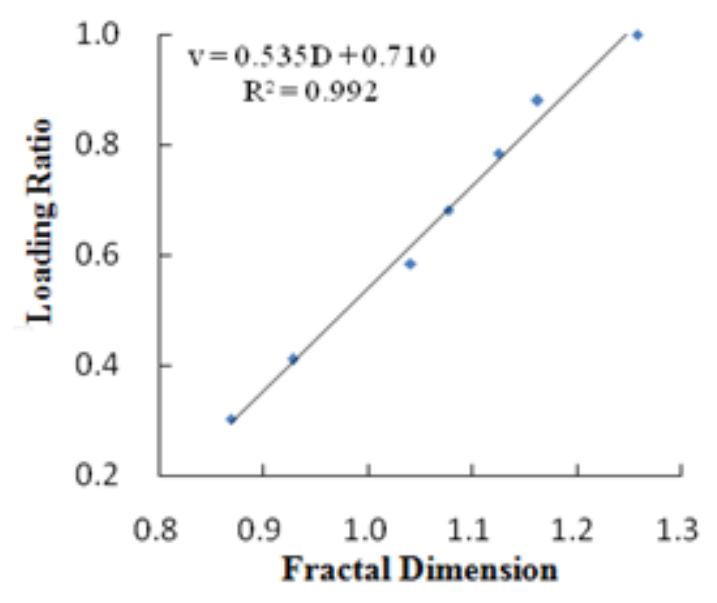

(c) RB-3

Fig. 2 The relationship between fractal dimension and loading ratio 
4.2 Relationship between fractal dimension and damage variable

With the increasing of the fractal dimension of its surface crack, the damage of the recycled concrete test beam occurs. Based on the characteristics of the structure damage, the damage variable $\omega$ is monotone increase in the damaging process. The damage variable $\omega$ under different loads and the fractal dimension of surface cracks hold the relationship of a quadratic function, as shown in Figure 3.

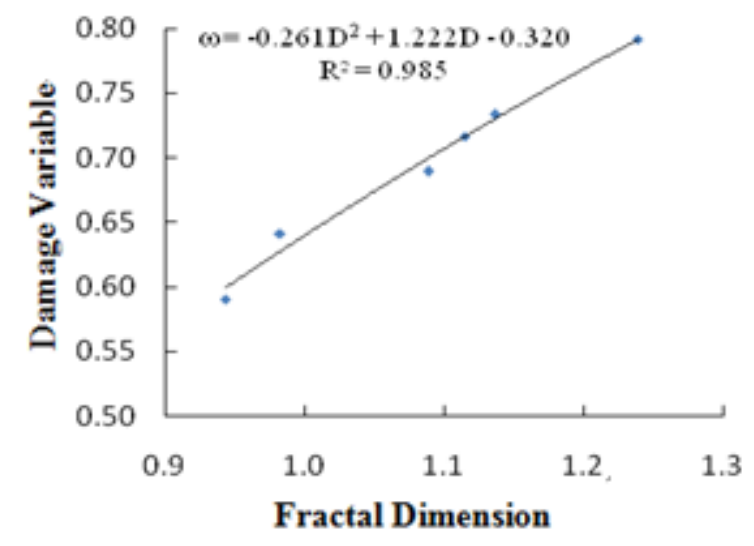

(a) RB-1

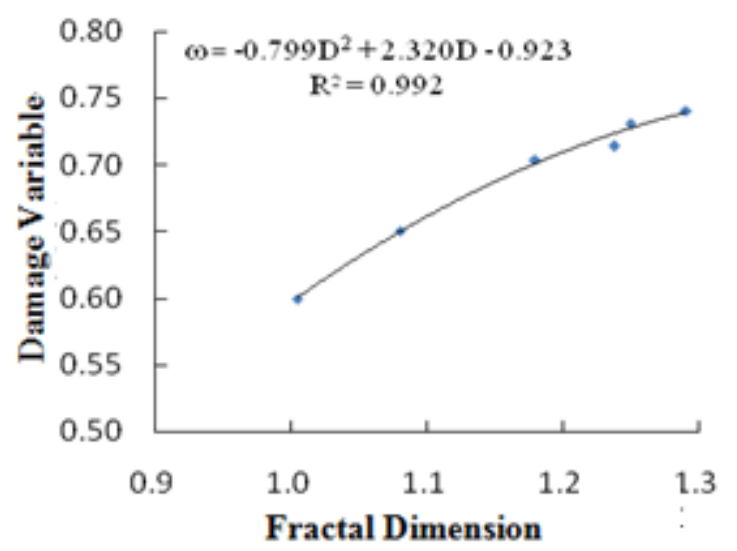

(b) RB-2

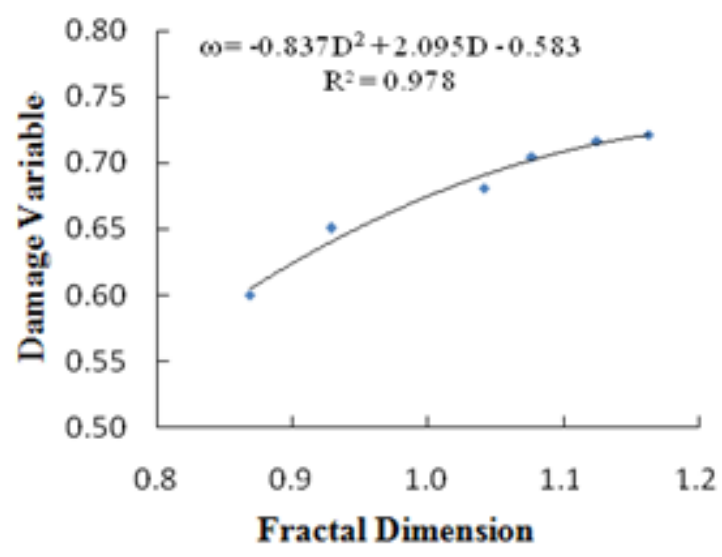

(c) RB-3

Fig.3 The relationship between fractal dimension and damage variable

\section{Conclusions}

(1) The surface crack extension of recycled coarse aggregate concrete beams under concentrated loads has the characteristics of fractals. The fractal dimension can be used to describe the distribution of the surface cracks quantitatively.

(2) The relationships between the fractal dimension and the damage variable and loads are established separately. The fractal dimension has a linear relationship with loads and a quadratic function relation with the damage variable.

(3) The different grading of recycled coarse aggregate has a significant effect on the crack propagation of the test beams. The fractal dimension can be used as the evaluation index of the damage degree of recycled coarse aggregate concrete beams. 


\section{References}

[1] LIU Shu-hua, LENG Fa-guong. Recycled Concrete Technology [M]. Beijing: China Building Materials Industry Press, (2007).

[2] SUN Hong-quan. Fractal Geometry and Fractal Interpolation [M]. Beijing: Science Press, (2011).

[3] SUN Hong-quan, DING Jun, GUO Jian, FU Dong-liang. Fractal Research on Cracks of Reinforced Concrete Beams with Different Aggregates Sizes[J]. Advanced Materials Research. (2011). p.1818-1822

[4] XIE He-ping. The Fractal Characteristics of Damage Evolution of Rock materials [J]. Journal of Rock Mechanics and Engineering. Vol. 10(1), (1991), p.74-82.

[5] SUN Hongquan, DING Jun. Fractal Research on Cracks of Reinforced Concrete Beams with Different Aggregates Sizes. Advanced Building Materials. (2011), p.1818-1822.

[6] LI Weitao, SUN Hongquan, XING Jun. Theory of Fractal Applied to Concrete Member [J]. Journal of Hebei University of Technology. Vol. 12(6), (2003), p.13-16.

[7] WANG Tie-cheng, YANG Jian-jiang, FANG Fan. Fractal Analysis for Crack State and its Extension of Concrete Structure [J]. Journal of Dalian University of Technology. Vol. (8), (1997), p.77-81. 